1. MBBS, MS General Surgery, DSS (AUS),

Fellowship in Reconstructive Micro Surgery.

Assistant Professor Department of Plastic Surgery Baqai Medical University Karach

2. MBBS, MS General Surgery.

Assistant Professo

Department of Surgery Baqai Medical University Karachi.

3. MBBS, FCPS Urology.

Assistant Professor

Department of Surgery/Urology

Baqai Medical University Karachi.

Correspondence Address:

Dr. Shafaatullah

Department of Surgery/Plastic Surgery

Baqai Medical University Karachi.

shafaatullah007@Hotmail.com

Article received on:

17/12/2018

Accepted for publication:

15/05/2019

Received after proof reading: 25/06/2019

\section{TO DETERMINE THE ADVANTAGE OF SNODGRASS REPAIR OF CONGENITAL HYPOSPADIAS AT DIFFERENT LEVEL OF PENILE SHAFT.}

\begin{abstract}
Shafaatullah', Sadaf Iqbal' ${ }^{2}$, Bilal Suria ${ }^{3}$
ABSTRACT... Hypospadias is a congenital defect with various presentations. It is diagnosed clinically. Hormonal therapy can be used but is not curative. The Snodgrass intervention is the better one to get result oriented outcomes. To find out the advantages of Snodgrass repair in distal as well as proximal types of hypospadias. Study Design: Cross sectional study. Setting: Baqai university hospital Karachi. Period: January 2015 to December 2017. Material and Method: Total 40 male patients were included in this study. They were admitted through OPD. Age of patients was from 4 years to 22 years. Patients were prepared and Snodgrass repair was done to all patients. Results: In our study, of 40, 19 (47.5\%) patients presented between age 04 to 10 years. Most common Subcoronal type was found in 16 (40\%). Catheter blockage was in $4(10 \%)$ patients that was a common complication in our study. Conclusion: To sum up, Snodgrass method is the good one with good cosmetic results and least complication rate.
\end{abstract}

Key words: $\quad$ Hypospadias, Meatal stenosis, Snodgrass, TIP, Urethroplasty.

\section{INTRODUCTION}

Hypospadias is defined as the congenital abnormality of urethral opening on the underside of penis. It is the most common congenital defect after cryptoorchididsm. ${ }^{1}$ It affects about one of every 250 males by birth. In $90 \%$ cases, meatus is near glans known as distal hypospadias whereas the remaining cases present with meatus near or within the scrotum called as proximal hypospadias. ${ }^{2}$

In most of the cases, foreskin is not wrapping around the penis due to its underdevelopment. Therefore glans of penis is not fully covered. This usually occurs in $10 \%$ of distal type and $50 \%$ in proximal type of Hypospadias. It is commonly associated with ventral curvature of the penis called chordee. Not only does this disease cause functional problems but also psychological ones also for parents and patients. Undescended testis is the common congenital abnormality associated with hypospadias. ${ }^{3,4}$

The diagnosis of this abnormality is usually clinical.
No specific investigation is needed. ${ }^{5}$ The treatment is usually surgical but preoperatively, androgen stimulation in the form of systemic testosterone, topical testosterone and dihydrotestosterone (DHT) and human chorionic gonadotropin (hCG) have been used to enhance the size of penis aimed at getting better results of tubularization of urethral plate and lessing the glans dehiscence incidence. The recent advances are discouraging the use of preoperative therapy of androgens. ${ }^{6}$

The only treatment with the best results is the early surgical intervention that can be performed at any age. Some advocate surgery from 3 months of age but it can be performed at any age even during adulthood. ${ }^{7}$ Previously many techniques were used for the repair of hypospadias but none of them produced satisfactory results. ${ }^{8}$ But in 1994, Warren Snodgrass invented a new procedure of tubularized incised plate (TIP) urethroplasty for distal penile hypospadias repair which latter on also was applied in proximal cases also. This technique is tension free tubularization of urethral plate and creates a new urethra. It is 
one stage procedure. Nowadays, this method is widely accepted and applied throughout globe. ${ }^{9}$ This is the procedure with least complications as compared to previously done surgical interventions with many complications like fistulae, urethral stricture, meatal stenosis, penile torsion, persistent chordee, infections and wound dehiscence. Snodgrass technique is the best one with many advantages over other procedures. ${ }^{10}$

The rationale of our study is to detect the advantages of Snodgrass repair so that it may widely be used for the benefit and betterment of all patients suffering from Hypospadias.

\section{MATERIAL METHODS}

This study has been conducted in Baqai University Hospital Karachi, during the time January 2015 to December 2017. All the patients were admitted through Out Patient Department (OPD). Total 40 male patients with diagnosis of all types of hypospadias were included. Patients aged from 4years to 22 years, recurrent cases, and hypospadias crippled were included in our study except those with marked chordee that leads to devitalization of the urethral plate.

After history taken from attendant and performing clinical examination, all the patients went under the process of required biochemical and radiological investigations. They underwent the Snodgrass repair. 3-0 silk suture is placed in the glans for traction and to later secure the urethral stent. A midline incision of urethral plate is given. Then the urethral plate is tubularized with interrupted 6-0 absorbable sutures in a tension free manner. A longitudinal dartos flap was harvested from dorsal preputial skin, which then brought ventrally and used to cover the ventral suture line. The catheter remained indwelling for 8-10 days. Patients were called for follow up and found good results with least complication rate.

\section{RESULTS}

The age of the patients were 4years to 22 years with median age $8.23 \pm 2.3$ years. The mean follow up was 04 months (range, 2 months to 10 months). 19 (47.5\%) patients came between 04 to 10 years of age. 15 (37.55) patients arrived between 11 to 16 years and only 6 (15\%) patients were admitted at the age of 17 to 22 years as is shown in Table-I.

In ourstudy, the mostcommon type of hypospadias is Sub-Coronal in $16(40 \%)$ patients, coronal in 7 (17.5\%), distal penile shaft in 10 (25\%), mid penile shaft in $4(10 \%)$, proximal penile shaft in 2 $(5 \%)$ and penoscrotal in $1(2.5 \%)$ patients only as is shown in Table-II below.

Of total 40 patients $12(30 \%)$ developed complications. Fistula formation, catheter blockage, meatal stenosis and wound infections in $1(2.5 \%), 4(10 \%), 4(10 \%)$ and $3(7.5 \%)$ respectively as is shown in Table-III.

\begin{tabular}{|l|c|c|}
\hline \multicolumn{1}{|c|}{ Age Variable } & No. Patients & Percentage \\
\hline 4 to 10 years & 19 & $37.5 \%$ \\
\hline 11 to 16 years & 15 & $47.5 \%$ \\
\hline 17 to 22 years & 6 & $15 \%$ \\
\hline Total & 40 & $100 \%$ \\
\hline
\end{tabular}

\begin{tabular}{|l|c|c|}
\hline Type of Hypospadias & $\begin{array}{c}\text { No of } \\
\text { Patients }\end{array}$ & Percentage \\
\hline Sub Coronal & 16 & $40 \%$ \\
\hline Distal penile shaft & 10 & $25 \%$ \\
\hline Coronal & 7 & $17.5 \%$ \\
\hline Mid penile shaft & 4 & $10 \%$ \\
\hline Proximal penile shaft & 2 & $5 \%$ \\
\hline PenoScrotal & 1 & $2.5 \%$ \\
\hline Total & 40 & $100 \%$ \\
\hline
\end{tabular}

Table-II. Type of hypospadias

\begin{tabular}{|l|c|c|}
\hline \multicolumn{1}{|c|}{$\begin{array}{c}\text { Postoperative } \\
\text { Complications }\end{array}$} & $\begin{array}{c}\text { No. of } \\
\text { Patients }\end{array}$ & Percentage \\
\hline Urethrocutaneous Fistula & 1 & $2.5 \%$ \\
\hline Catheter Blockage & 4 & $10 \%$ \\
\hline Meatal Stenosis & 4 & $10 \%$ \\
\hline Wound Infection & 3 & $7.5 \%$ \\
\hline Total & 12 & $30 \%$ \\
\hline \multicolumn{2}{|c|}{ Table-III. Postoperative complications } \\
\hline
\end{tabular}




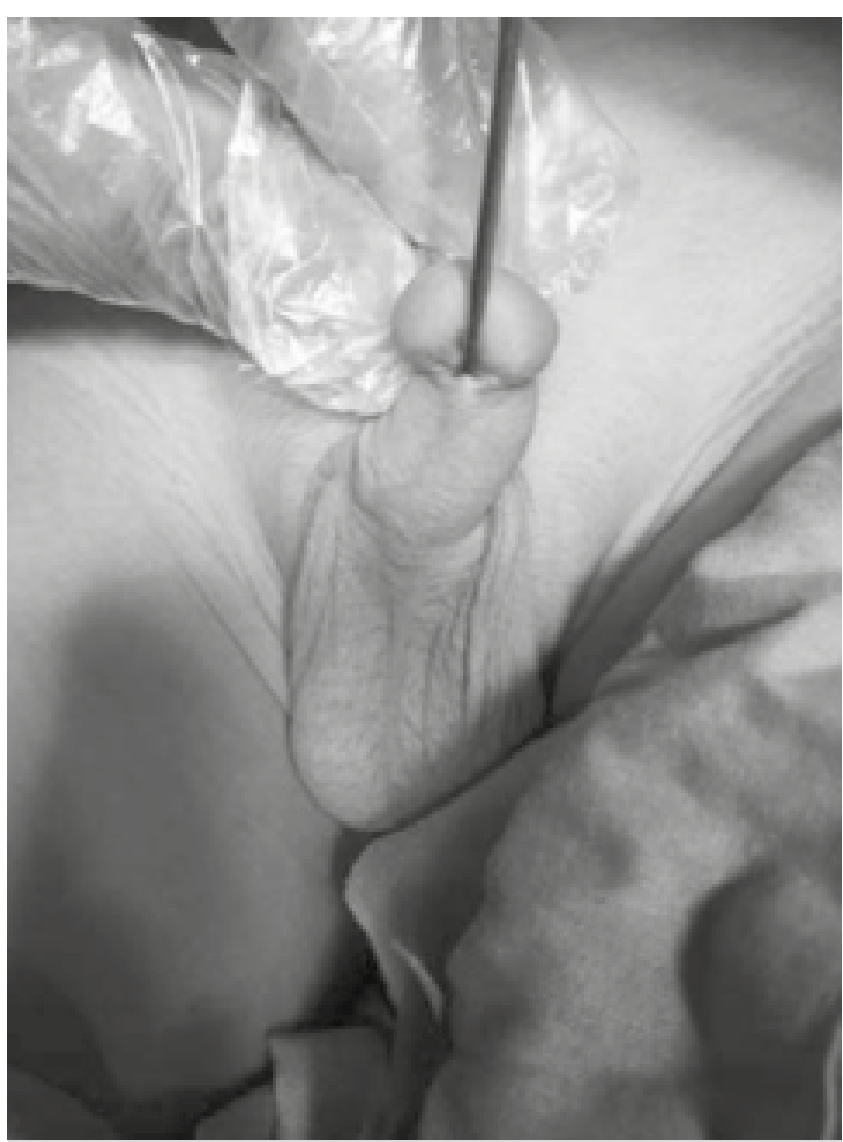

Figure-1. Assessment of subcoronal hypospadias

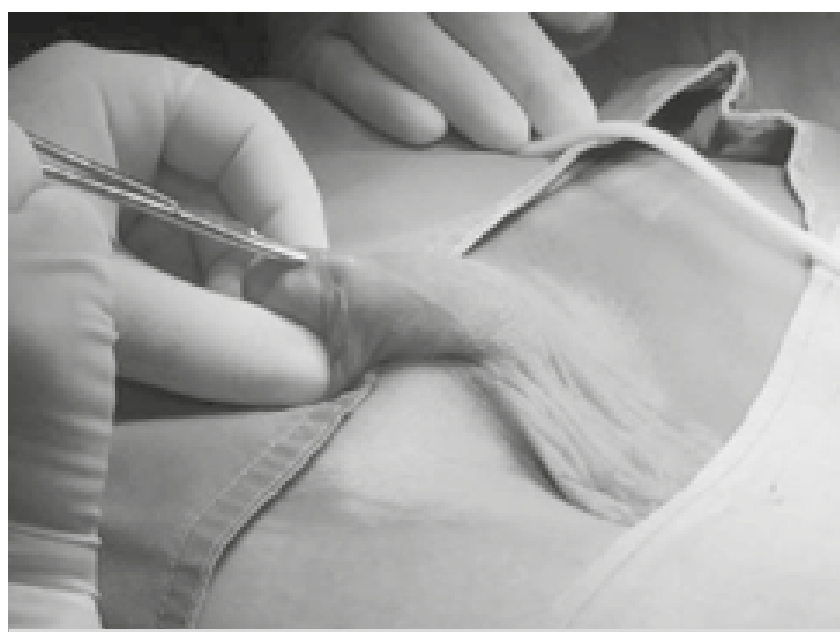

Figure-2. Assessment of coronal hypospadias

\section{DISCUSSION}

Hypospadias is the congenital defect affecting the one male baby out of 250 to 300 . The most common type is the distal hypospadias. Though the Snodgrass urethroplasty has been used for distal type by many urologist but many also use it for proximal one also. ${ }^{11}$

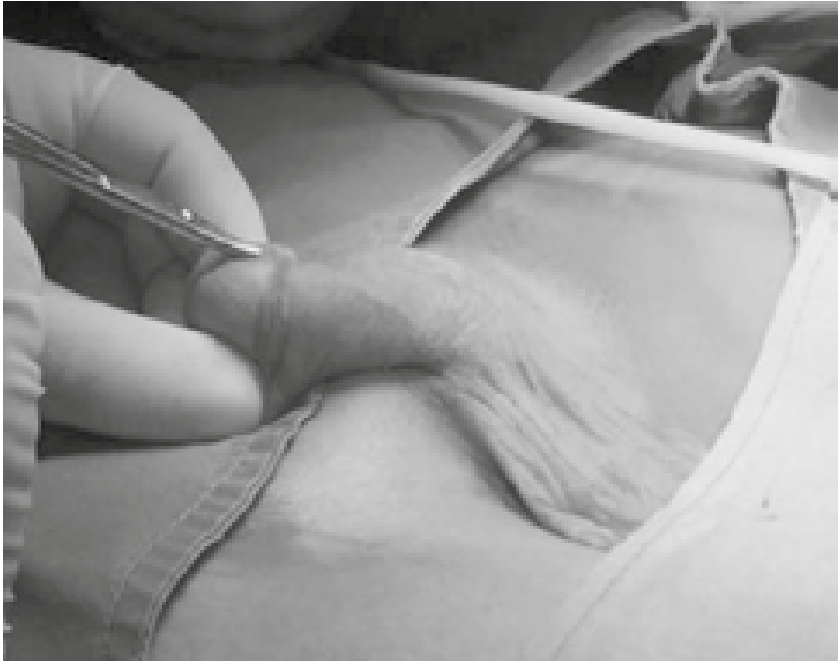

Figure-3. Assessment of coronal hypospadias

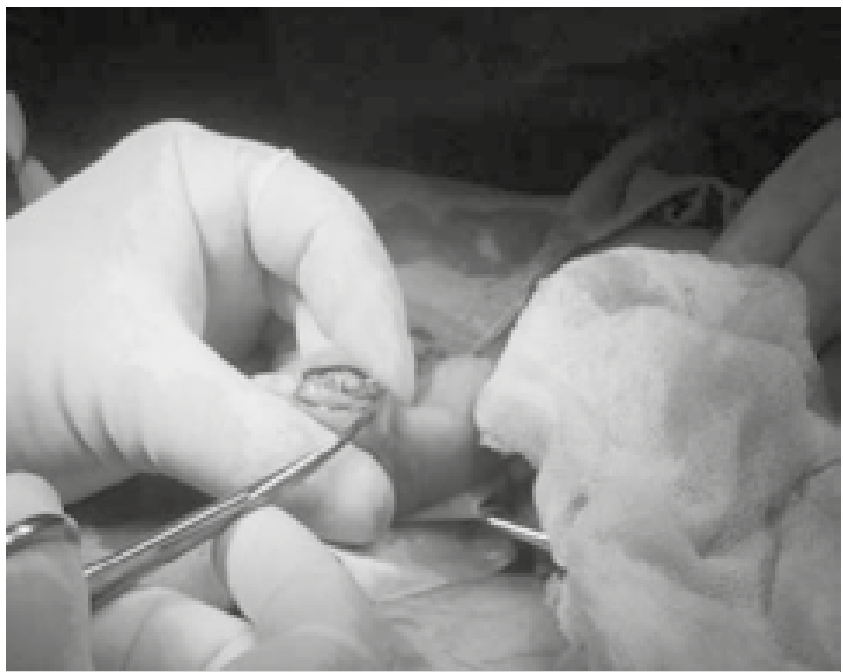

Figure-4. Post urethral plate tubularization

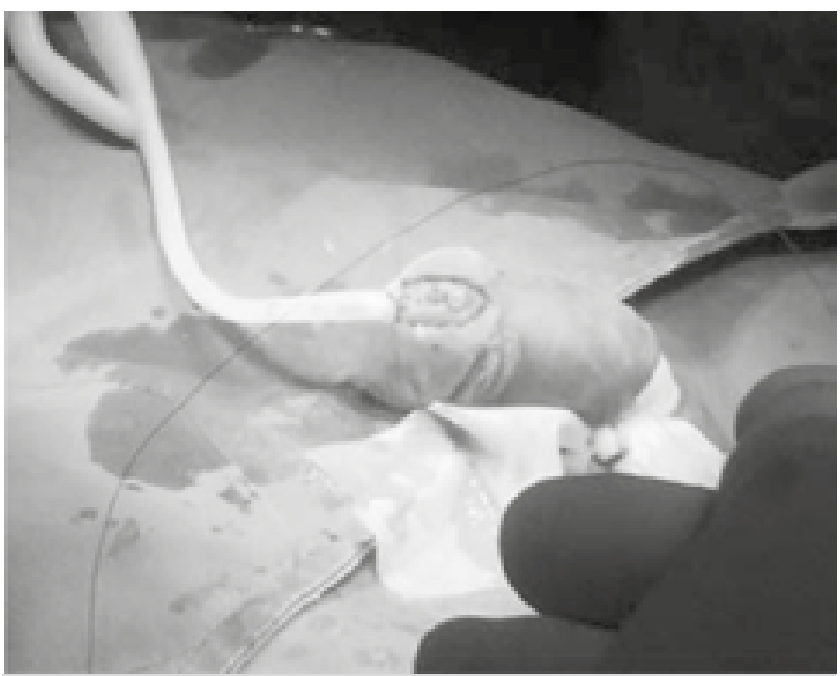

Figure-5. Post urethral plate tubularization 


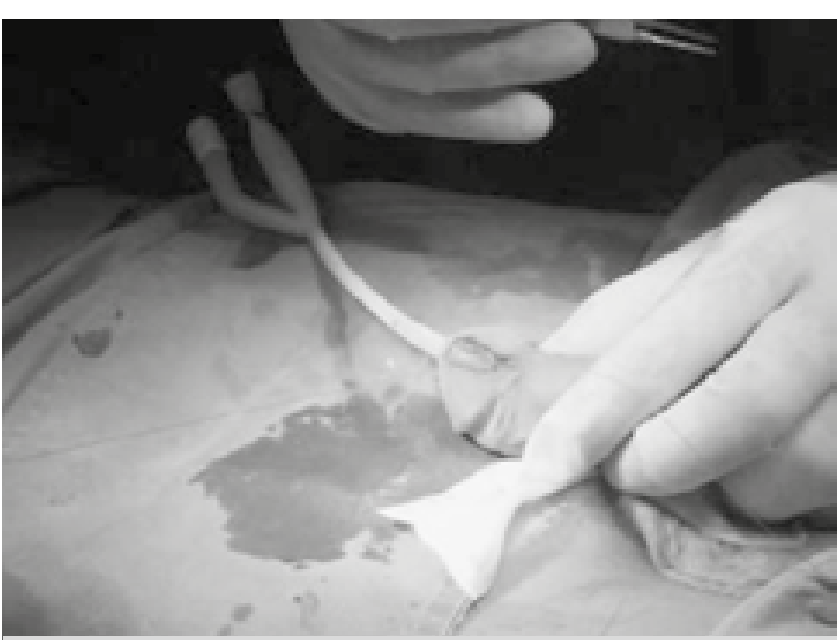

Figure-6. Post urethral plate tubularization

After the declaration of Snodgrass technique, all other procedures to repair this disease were discouraged by the urologist due to their multiple frequent complications but this technique revolutionized the results in this context. It has high success rates as is also concluded in our study. After this procedure, the appearance of meatus is very look like normal. It is done in one stage. This is another advantage. . $^{12,13}$

In a study conducted for five years in Saudi Arabia from 2007 to 2012, this procedure showed good results with least complications. ${ }^{14}$ Our study also proved this fact with lowest complication rate. Another study in Turkey demonstrated excellent cosmetic outcomes after using mucosal collars. In this study the complications were fistula and meatal stenosis with $8.3 \%$ and $14 \%$ respectively. ${ }^{15}$ But in our study urethrocutaneous fistula was only $2.5 \%$ and meatal stenosis only in $10 \%$ of Patients. The complication of meatal stenosis can be decreased by the use of lay graft plus the preputial vascularised dartos flap. ${ }^{16}$

Various studies suggest the use of testosterone injections or topical creams increase the length and circumference of the penis and few show the effect of this treatment on the outcome of surgery with varying opinions. ${ }^{17,18}$ Therefore the role of hormone therapy prior to surgery is still unclear. ${ }^{19}$

\section{CONCLUSION}

In short, it can be concluded that hypospadias either distal or proximal are best treated by Snodgrass method with least complications rate. It frees patients from functional as well as psychological impact of this disease on parents as well as patients. The addition of dartos flap results in prevention of complications.

\section{Copyright $@ 15$ May, 2019.}

\section{REFERENCES}

1. Ruppen-Greeff NK, Weber DM, Gobet $R$, et al. Health-related quality of life in men with corrected hypospadias: An explorative study. J Ped Urol. 2013; 9:551-8.

2. Keays MA, Starke N, Lee SC, et al. Patient reported outcomes in preoperative and postoperative patients with hypospadias. J Urol. 2016; 195:1215-20.

3. Kumar S, Tomar V, Yadav SS, et al. Fertility potential in adult hypospadias. J Clinc Diagn Res J Urol. 2016; 10:PC01-5.

4. Hoy NY, Rourke KF. Better defining the spectrum of adult hypospadias: Examining the effect of childhood surgery on adult presentation. Urology. 2016; 16:30628-8.

5. Hueber P-A, Antczak C, Abdo A, et al. Long-term functional outcomes of distal hypospadias repair: A single-centre, retrospective comparative study of TIPs, Mathieu, and MAGPI. J Pediatr Urol. 2015; $11: 68 \mathrm{e} 1-7$.

6. Rynja SP, de Jong TP, Bosch JL, et al. Functional, cosmetic and psychosexual results in adult men who underwent hypospadias correction in childhood. $J$ Pediatr Urol. 2011; 7:504-15.

7. Mousavi SA, Aarabi M. Tubularized incised plate urethroplasty for hypospadias reoperation: A review and meta-analysis. Int Braz J Urol. 2014; 40:588-95.

8. Long CJ, Chu DI, Tenney RW, et al. Intermediate-term followup of proximal hypospadias reveals high complication rate. J Urol. 2016; 16:31748-7.

9. Gundeti M, Queteishat A, Desai D, et al. Use of an inner preputial free graft to extend the indications of Snodgrass hypospadias repair (Snodgraft) J Pediatr Urol. 2005; 1:395-6.

10. Hassan HS, Almetaher HA, Negm M, et al. Urethral mobilization and advancement for distal hypospadias. Ann Pediatr Surg. 2015; 11:239-43.

11. Steven L, Cherian A, Yankovic F, et al. Current practice in pediatric hypospadias surgery: $A$ specialist survey. J Pediatr Urol. 2013; 9:1126-30. 
12. Baillargeon $E$, Duan $K$, Brzezinski $A$, et al. The role of preoperative prophylactic antibiotics in hypospadias repair. Can Urol Assoc J. 2014; 8:236-40.

13. Zeiai S, Nordenskjold A, Fossum M. Advantages of reduced prophylaxis after tubularized incised plate repair of hypospadias. J Urol. 2016; 196:1244-9.

14. Chalmers DJ, Siparsky GL, Wiedel CA, et al. Distal hypospadias repair in infants without a postoperative stent. Pediatr Surg Int. 2015; 31:287-90.

15. Malik RD, Liu DB. Survey of pediatric urologists on the preoperative use of testosterone in the surgical correction of hypospadias. J Pediatr Urol. 2014; 10:840-3.
16. Netto JMB, Ferrarez CEPF, Leal AAS, et al. Hormone therapy in hypospadias surgery: A systematic review. J Pediatr Urol. 2013; 9:971-9.

17. Snodgrass W, Bush N. Primary hypospadias repair techniques: A review of the evidence. Urology Ann. 2016; 8:403-8.

18. Steven L, Cherian A, Yankovic F, et al. Current practice in pediatric hypospadias surgery: A specialist survey. J Pediatr Urol. 2013; 9:1126-30.

19. Snodgrass WT, Bush NC. Reoperative urethroplasty after failed hypospadias repair: How prior surgery impacts risk for additional complications. J Ped Urol. 2016.

\section{AUTHORSHIP AND CONTRIBUTION DECLARATION}

\begin{tabular}{|c|l|l|l|}
\hline Sr. \# & Author-s Full Name & \multicolumn{1}{|c|}{ Contribution to the paper } & Author=s Signature \\
\hline 1 & Shafaatullah & $\begin{array}{l}\text { Concept and design, Statistical } \\
\text { expertise, Critical revision of the article } \\
\text { for important intellectual content. } \\
\text { Data collection, Critical revision of } \\
\text { the article for important intellectual } \\
\text { content. } \\
\text { Drafting of the article. }\end{array}$ \\
\hline 3 & Bilal Suria & Sadaf lqbal & \\
\hline
\end{tabular}

